\title{
超小型試験片を用いたマスターカーブ破壊勒性評価
}

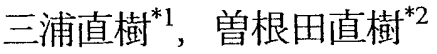

\section{Evaluation of Fracture Toughness by Master Curve Approach Using Miniature Specimens}

\author{
Naoki MIURA ${ }^{* 3}$ and Naoki SONEDA \\ $*^{3} \quad$ Central Research Institute of Electric Power Industry \\ 2-6-1 Nagasaka, Yokosuka-shi, Kanagawa-ken, 240-0196 Japan
}

\begin{abstract}
The fracture toughness Master Curve gives a universal relationship between the median of fracture toughness and temperature in the ductile-brittle transition temperature region of ferritic steels such as reactor pressure vessel (RPV) steels. Considering the possible application of the Master Curve method coexistent with the present surveillance program for operating RPVs, the utilization of miniature specimens is quite important for efficient determination of the Master Curve from limited volume of the materials of concern. In this study, fracture toughness tests were conducted for typical Japanese RPV steels using the miniature $C(T)$ specimens with the thickness of $4 \mathrm{~mm}$ following the procedure of the ASTM standard. The results showed that the differences in test temperature, evaluation method, and specimen size did not affect the Master Curves, and the fracture toughness indexed by the reference temperature, $T_{o}$, obtained from miniature $\mathrm{C}(\mathrm{T})$ specimens were consistent with those obtained from standard and larger $\mathrm{C}(\mathrm{T})$ specimens.
\end{abstract}

Key Words : Fracture Toughness, Master Curve Method, Reactor Pressure Vessel, Miniature C(T) Specimen

\section{1. 緒 言}

経年化した原子炉圧力容器の構造健全性を正しく評

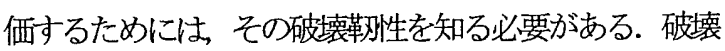
靭性の評価曲線は温度に対する破壊革狌值の下限包絡線

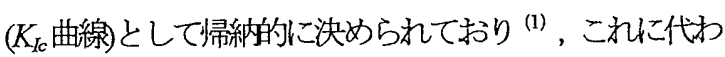
るより合理的な破壊勒性評価法が求められている. 近年, 破壊革性が本来有する統計分布特性を考慮してその信頼 限界を理論的に定める，いわゆるマスターカーブ法 ${ }^{(2)}$ が提案された。同法は，同一条件下にお汸るフェライト 鋼の破壊靸生のばらつきを最弱リンクモデルに基づくワ イブル分布により記术し，が分布の平均値の温度依存 性を，鋼材によって決まる参照盜度を唯一のパラメータ とする一本の曲線によって記述する手法であり, 破壊勒 性の下限值の合理的な設定を可能とするものである.こ れまでに国産原子炉圧力容器(RPV)鋼を対象とした体系

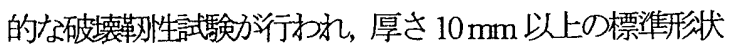
試験片を用いればマスターカーブ法が適用可能であるこ とが明らかれされている(3,4)。

${ }^{+1}$ 正員，（財）電力中央研究所（T240-0196 神奈川県横須賀 市長坂 2-6-1)

"2正員, (財) 電力中央研究所.

E-mail: miura@criepi.denken.or.jp
マスターカーブ法を実用化するためには，現行の監視 試験プログラムと共存し得る評価法の確立が不可欠であ る.このためには, 使用済みの監視試験片を再利用して 試験片か採取できる、いわゆる超小型試験片を利用する ことの可否が大きな键を握る. 本研究では，代表的な国 産RPV 鋼を対象として, いわゆる監視試験片よりも小さ な寸法の詿験片を用いた破壊革刏性試験を行い，マスター カーブ破填靭性評価法への超小型試験片の適用性と実現 可能性とについ検討を行った。

\section{2 マスターカ一フ法の概要}

マスターカーブとは遷移温度領域における破壊靭生 の中間值 $K_{J(\operatorname{mad})}$ と温度 $T$ の関係を規定する曲線であり, その形伏は鋼材によらず一定である. 鋼材の違いによる 破壊勒性の大小は，マスターカーブがその形状を保持し たままで温度軸に沿って左右にシフトすることで表現さ

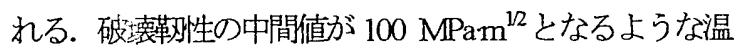
度を参照温度 $T_{o}$ と称し，マスターカーブの位置を特定す る指標として用いられる. マスターカーブは次式により 与えられる.

$$
K_{J c(\text { med })}=30+70 \exp \left[0.019\left(T-T_{o}\right)\right]
$$

評価の詳絴については関連基淮 (5) を参照されたい．

日本機械学会 [No.10-9] M\&M2010材料力学カンファレンス CD-ROM論文集 [2010.10.9-11,長岡〕 
Table 1 Chemical composition of tested materials

\begin{tabular}{c|c|c|c|c|c|c|c|c|c|c}
\hline Material & $\mathrm{C}$ & $\mathrm{Si}$ & $\mathrm{Mn}$ & $\mathrm{P}$ & $\mathrm{S}$ & $\mathrm{Ni}$ & $\mathrm{Cr}$ & $\mathrm{Mo}$ & $\mathrm{V}$ & $\mathrm{Cu}$ \\
\hline SFVQ1A & 0.18 & 0.18 & 1.46 & 0.002 & 0.001 & 0.90 & 0.12 & 0.52 & $<0.01$ & - \\
\hline SQV2A(Heat 1 & 0.22 & 0.25 & 1.44 & 0.021 & 0.028 & 0.54 & 0.08 & 0.48 & - & 0.10 \\
\hline SQV2A(Heat 2 & 0.22 & 0.25 & 1.46 & 0.002 & 0.002 & 0.69 & 0.11 & 0.57 & - & - \\
\hline
\end{tabular}
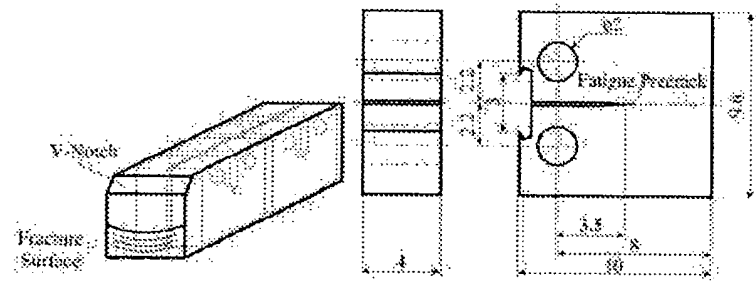

Fig. 1 Miniature $\mathrm{C}(\mathrm{T})$ specimen

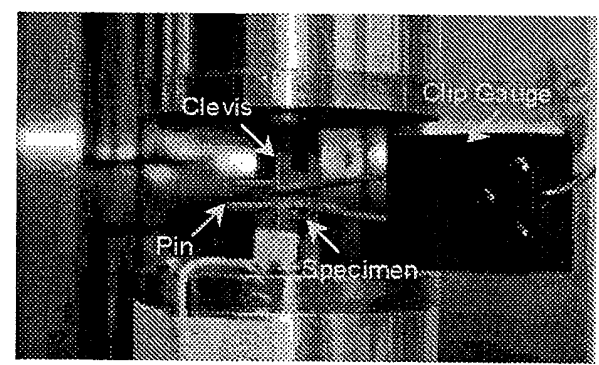

Fig. 2 Setup of miniature $\mathrm{C}(\mathrm{T})$ specimen

\section{3. マスタ一カ一フ破壊靬性試験}

3 -1 供試材とその引張特性 詿験に优国産の原子 炉圧力容器用材料である SFVQ1A 鋼 1 ヒート, および SQV2A 鋼 2 ヒートを供試した。前者はASTM規格に定 めるA508Cl. 3鋼に，また後者はA533 Gr. BCl 1 鋼こそ れぞれ相当する. 供試材の化学組成を表 1 に示寸. これ ら供試材については温度をパラメータとする丸棒引張武

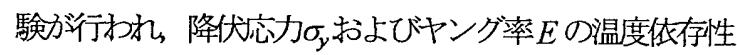
が鋼種によらす次式のとおり得られている(3)。

$$
\begin{aligned}
& \sigma_{y}=84+271 \exp \left(\frac{110}{T}\right), \sigma_{y} \text { in }[\mathrm{MPa}], T \text { in }[\mathrm{K}](2) \\
& E=210-0.063(T-20), E \text { in }[\mathrm{GPa}], T \text { in }\left[{ }^{\circ} \mathrm{C}\right](3)
\end{aligned}
$$

3 -2 試験片＼cjkstart試験には破断後のシャルピー試験片 から採取，加工した公称板㫗 $4 \mathrm{~mm}$ のミニチュアC(T)試 験片を用いた。試験片の採取要領および寸法形状を図 1 に示寸. C(T)圾験片では通常変形量として荷重線変位を 計測するが，試験片が小さく荷重線上での変位計測が困 難なため, 圾験片の前面にナイフエッジを設け，前面で の変位を荷重線变位に補正して破壊革对生の評価を実施し た ${ }^{(6)}$ 。すへての詿験片には，初期き裂長さの試験片幅に 対する比 $a_{0} W$ が 0.5 となるようなき裂長さを目標として 疲労予き裂蓬導入した。
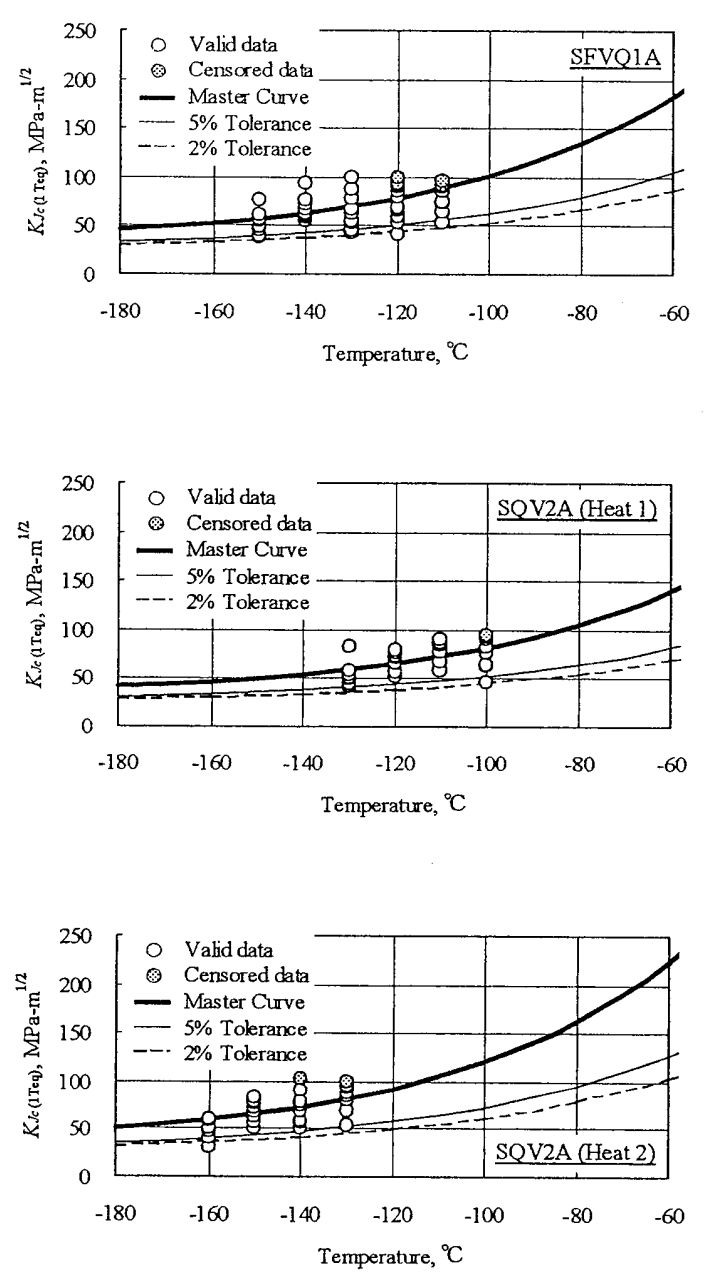

Fig. 3 Master Curves and fracture toughness data

3 -3 試験方法 試験片に淮静的な単調引張荷重を 負荷し，試験片にへき開破壊を生じるまでの荷重と圾験 片前面变位を計測し，ASTM 基淮 ${ }^{(5)}$ に定める手順に従 い破壊革性 $K_{K_{c}}$ を評価した. 想定される $T_{o}$ に㐫じて適切 な詿験温度を設定した。玟験終了後, 破断した試験片よ

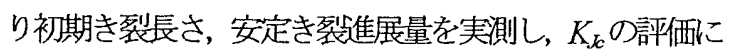
用いた。詰験片の詿験機への設置状況を図 2 に示す。

3 -4 試联結果 註験の結果得られた破壊勒性と $T$ の関係をマスターカーブおよびその $5 \% ， 2 \%$ 信束面限界と 併せて材料ごとに図 3 に示す。破壊䩠にはは厚さ1イン チの䚾験片に補正した值 $K_{\text {Ja(Tes) }}$ を用いた. ASTM基淮 (5) の規定に照らして個々のデータの有效性(Validity)の判定 を行い，K， K゙その上限值を超える無効なデータ (Invalid data)はダミーデータ(Censored data)に置き換えてある. す べてのデータはマスターカーブを中心炕分布しており，

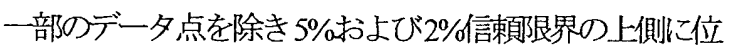
置している.これら信頼限界で包絡される圾験デー夕の 


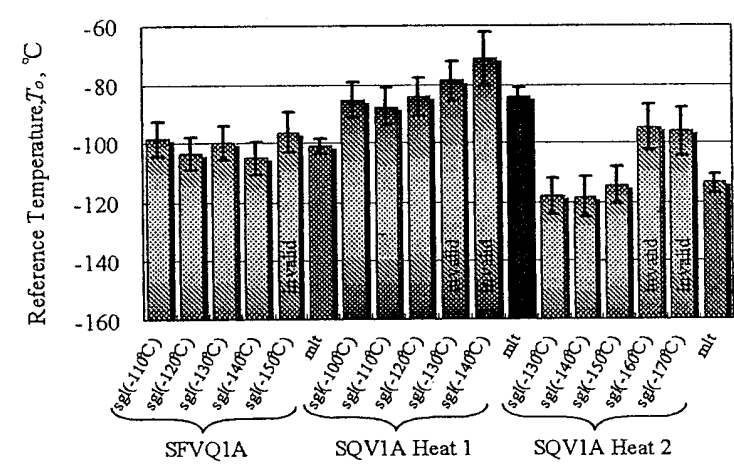

Fig. 4 Effect of test temperature on reference temperature

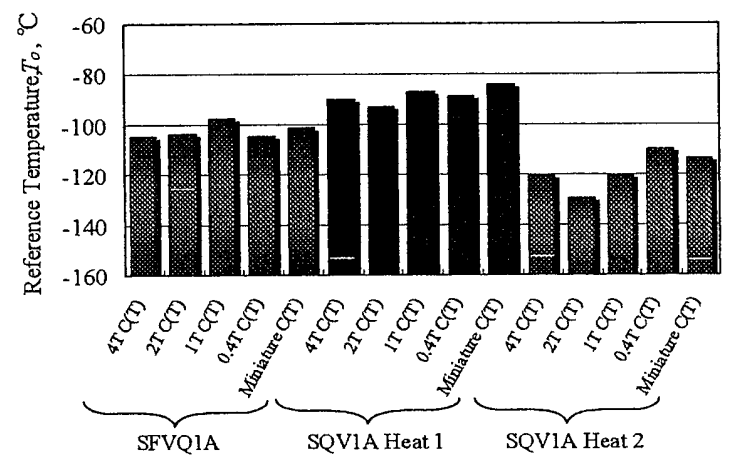

Fig. 5 Effect of specimen size on reference temperature

割合はそれぞれ 94\%，98\%であり，概ね想定通りの結果 である.

$T_{o}$ の訪験温度に対する依存性を図 4 に示卞. 図中の "sglおよび"mit"はそれぞれ単一温度法，複数温度法によ る評価結果を示し，またエラーバーは各ケースに掠ける $\pm \sigma_{T o}\left(T_{o}\right.$ の標準扁差を表す. 単一温度法のうち詿験温度が 相対的に高レケースについては， $T_{0}$ の決定に用いた破壊 靸性力゙適正な温度範用 $\left(T_{0}-50^{\circ} \mathrm{C}\right.$ 加 $\left.T_{0}+50^{\circ} \mathrm{C}\right)$ て取得され ていとの要件を゙満たしておらず,これを図中に Invalid と表記している. 同一材料について複数温度法により得 られた $T_{0}$ を基淮に考えると, 単一温度法により得られた Valid な $T_{o}$ の違いはたかだか $4.7^{\circ} \mathrm{C}$ に過ぎず， $T_{o}$ が Valid でありさえすれは試験温度の依存性は小さい，

既往研究の結果 ${ }^{(3)}$ とともに複数温度法による $T_{o}$ の試 験片寸法に対する依存性を図 5 に示す。厚さ $100 \mathrm{~mm}$ の $4 \mathrm{~T} \mathrm{C}(\mathrm{T})$ 詿験片から厚さ $4 \mathrm{~mm}$ のミニチュアC(T)試験片 まで $T_{0}$ は良好に一致しており, 平均值からの最大の偏差 はSFVQ1A鋼，SQV2A鋼ヒート1, およひ可鋼ヒート2 でそれぞれ $4.8^{\circ} \mathrm{C}, 4.5^{\circ} \mathrm{C}, 10.5^{\circ} \mathrm{C}$ であった. 本研究で詨 象とした材料しついては、ミニチュアC(T)詰験片を用い ても標準C(T)坛験片を用いた場合と同等の $T_{0}$ を評価する ことができるといえる.

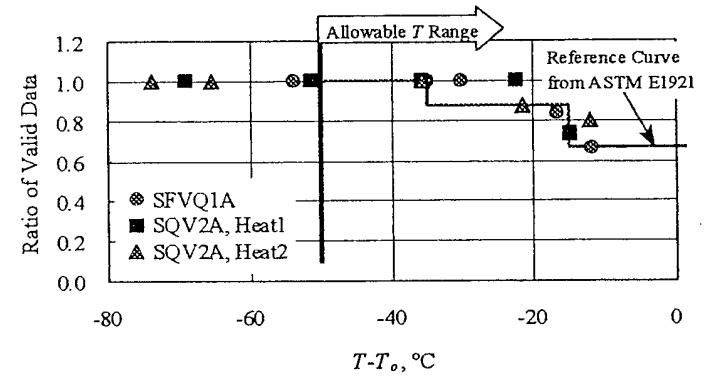

Fig. 6 Relation between ratio of valid data and $T-T_{0}$

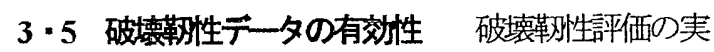
機商用にあたり， $T_{o}$ を定めるために Valid なデータをい が效率的に取得できるかが重要な問題となる. 本圾験 において Valid なデータが取得された割合を $T-T_{0}$ てて整理 して図6に示す.Validなデータの割合はT-Toが小さくな るにつれて増加し、ほぼ $30^{\circ} \mathrm{C}$ 以下のときに 1 となって取 得データがすべて Valid となる. すなわち，ミニチュア $\mathrm{C}(\mathrm{T})$ 詿験片に沶いては， $T_{0}-30^{\circ} \mathrm{C}$ から $T_{0}-50^{\circ} \mathrm{C}$ の範囲でデ 一夕を註験を行えば “無䭾のない”デー夕の取得が可能 となり,この傾句は材料こよらない．

\section{4. 結言}

代表的な国産原子炉圧力容器鋼である SFVQ1A 鋼, SQV2A 鋼を刘象として, 厚さ $4 \mathrm{~mm}$ のミニチュアC(T) 詿験片を用いた 140 体の破壊勒性坛験を行い，同詰験片 のマスターカーブ破壊䗌生評価法への適用性について検 討を行った. ASTM 基淮に規定された評価手順に従、， 材料ごとに有効な参照温度を決定することができた： ニチュアC(T)訌験片によっても標潗試験片寸法以上の試 験片と同等の参照温度を決定できることを確垫した。

\section{文献}

(1) Japan Electric Association, Method of Verification Tests of the Fracture Toughness for Nuclear Power Plant Components, JEAC4206-2007, (2007).

(2) Wallin, $K$., The Scatter in $K_{I c}$ Results, Engineering Fracture Mechanics, Vol. 9, (1984), pp. 1085-1093.

(3) Miura, N. et al., Applicability of Master Curve Method to Japanese Reactor Pressure Vessel Steels, Proceedings of PVP2006-ICPVT-11, 93792, (2006).

(4) Tomimatsu, M. et al., Master Curve Approach for Some Japanese Reactor Pressure Vessel Steels, Proceedings of PVP2008, 61494, (2008).

(5) American Standard for Testing and Materials, Standard Test Method for Determination of Reference Temperature, $T_{o}$, for Ferritic Steels in the Transition Range, ASTM E1921-08a, (2008).

(6) Miura, N. and Soneda, N., Evaluation of Fracture Toughness by Master Curve Approach Using Miniature $\mathrm{C}(\mathrm{T})$ Specimens, Proceedings of PVP2010, 25862, (2010). 